\title{
Atividade antimicrobiana do alho (Allium sativum L.) frente a bactéria causadora de infecção do trato urinário
}

\author{
Fabiano Freire Caldas ${ }^{\mathrm{a}}$, Jeronimo Pereira Silva Filho ${ }^{\mathrm{a}}$, Carla Andreia Rezende Rodrigues ${ }^{\mathrm{a}}$, \\ Diego Pereira da Silva ${ }^{a^{*}}$ \\ ${ }^{a}$ Faculdade Integrada Carajás (FIC), Redenção (PA), Brasil \\ *Autor correspondente (professorpereira@outlook.com)
}

\section{N F O}

Keywords

natural antibiotics

essential oil

inhibition halo

Escherichia coli
Palavras-chaves antibióticos naturais óleo essencial halo de inibição Escherichia coli

\begin{abstract}
A B S T R A C T
Antimicrobial activity of garlic (Allium sativum L.) against bacteria causing urinary tract infection. One of the most prevalent forms of infection worldwide is urinary tract infection, and it can be determined as: cystitis, lower urinary tract infection, bladder infection or as pyelonephritis which is the most severe form of this condition where the infection settles in the ureters and kidneys. In most cases the infection is caused by the bacterium Escherichia coli. Several alternative methods based on plants or plant extracts are tested for treatments that replace synthetic antibiotics. This study aimed to analyze the in vitro antibacterial activity of garlic essential oil (Allium sativum L.) And garlic extract against Escherichia coli bacteria. The essential oil and garlic extracts were diluted to $100 \%, 50 \%$ and $25 \%$ concentrations and applied to medium containing E. coli strains together with conventional antibiotics ciprofloxacin and levofloxacin for comparison of halo on antibiogram. After incubation for 24 hours at $36^{\circ} \mathrm{C}$, the results showed that the essential oil did not show satisfactory results, while garlic extract obtained halos (mm) at all concentrations analyzed $(100 \% 13.33 \pm 2.5950 \% 9.22 \pm 1.48$ and $25 \% 6.22 \pm 4.27$ and the $100 \%$ concentration obtained remarkable circumferences very close to those created by the conventional antibiotics ciprofloxacin $(11.56 \pm 4.27)$ and levofloxacin $(13,44 \pm 3,43)$ Further studies should be done to propose alternatives for using garlic extract in the formulation of cosmetics or even herbal medicines that aim to eliminate or even inhibit the development of E.coli.
\end{abstract}

\section{R E S U M O}

Uma das formas de infecção mais predominante em todo mundo é a infecção do trato urinário, e pode-se determiná-la como: cistite, infecção do trato urinário baixo, infecção da bexiga ou como pielonefrite que é a forma mais grave desta patologia, onde a infecção se instala nos ureteres e rins. Na maioria dos casos a infecção é causada pela da bactéria Escherichia coli. Vários métodos alternativos com base em plantas ou extratos vegetais são testados a fim de se obter tratamentos que substituem os antibióticos sintéticos. O presente estudo teve como objetivo realizar a análise da atividade antibacteriana in vitro do óleo essencial do alho (Allium sativum L.) e do extrato de alho frente bactéria Escherichia coli. O óleo essencial e os extratos do alho foram diluídos nas concentrações $100 \%, 50 \%$ e $25 \%$ e aplicados em meio contendo as cepas de $E$. coli juntamente com os antibióticos convencionais ciprofloxacina e levofloxacina para comparação de halo no antibiograma. Após incubação por 24 horas a $36^{\circ} \mathrm{C}$, os resultados obtidos mostraram que o óleo essencial não apresentou resultado satisfatório, já o extrato de alho obteve

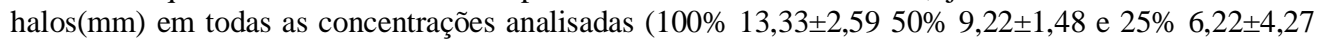
sendo que a concentração de $100 \%$ obteve circunferências notáveis e muito próximas dos criados pelos antibióticos convencionais ciprofloxacina $(11,56 \pm 4,27)$ e levofloxacina $(13,44 \pm 3,43)$. Mais estudos devem ser feitos para propor alternativas de utilização do extrato do alho na formulação de cosméticos ou mesmo medicamentos fitoterápicos que tenham o objetivo de eliminar ou mesmo inibir o desenvolvimento de E.coli. 


\section{INTRODUÇÃO}

A utilização de plantas medicinais e produtos fitoterápicos têm sido bastante utilizados para o tratamento de enfermidades por parte da população, especialmente as mais carentes e de difícil acesso aos medicamentos tradicionais (Gazola; Singi e Resende, 2002).

Devido ao aumento da resistência bacteriana, as plantas medicinais vêm sendo bastante utilizadas, tanto para tratamento de doenças, e para estudo de propriedade antibacteriana, uma vez que possuem inúmeras substâncias biologicamente ativas (Rossi e Andreazzi, 2005).

Vale destacar as características das ervas aromáticas e especiarias e a sua capacidade antioxidante atribuída à sua riqueza em vários compostos fenólicos. Estes compostos neutralizam os radicais livres ajudando assim a prevenir o aparecimento de algumas doenças graves, como a doença inflamatória crônica e tumores (Cohain, 2010). Sabe-se que a sua aplicação pode ter efeitos benéficos na saúde, especialmente na prevenção de doenças como a diabetes, hipertensão arterial, entre outros (Paur, 2011).

Sandhu e Heinrich (2005), afirmam que por essa razão as plantas medicinais são consumidas, muitas vezes, como auto tratamento e podem ser vistas como novas formas e alternativas de tratamento na medicina. Atualmente o acesso a produtos naturais é cada vez mais facilitado e dado o efeito que as especiarias e ervas aromáticas podem ter na saúde, é importante conhecer melhor o seu papel na culinária e nas aplicações farmacêuticas (Lima et al., 2006).

Roriz Filho et al. (2010), confirmam que a infecção do trato urinário é comum, pois ocorre desde o recém-nascido ao idoso, as mulheres são acometidas desta infecção do trato urinário com frequência devido a sua estrutura anatômica, uretra mais curta e proximidade entre a vagina e o ânus. A infecção ocorre por via ascendente trato urinário inferior (cistite) ou trato urinário superior (pielonefrite).

Estudos demonstram que o diagnóstico tardio de infecção do trato urinário, aumenta o risco de problemas renais, deixando o paciente com sequelas, como insuficiência renal e hipertensão arterial sistêmica. Os agentes etiológicos mais encontrados na população por ordem são: Escherichia coli, Klebsiella, Staphylococcus saprophyticus e Enterococcus faecalis. A E. coli, sozinha, responsabiliza-se por 70 a $85 \%$ das infecções do trato urinário adquiridas pela população (Lopes e Tavares, 2005).

O alho (Allium sativum L.) é uma planta herbácea, pertencente à família Alliaceae, as folhas são lineares e extensas e as flores reunidas em umbela branca ou vermelhadas longo - penduculada, e é conhecida por vários nomes dependendo da região como: alho-comum, alho-ordinário, alho-hortense, alho-vulgar, alho-manso e alho do reino, seus constituintes químicos encontra-se em maior quantidade nos bulbo, o seu óleo essencial contém aproximadamente 53 constituintes químicos principalmente ajoeno, alicina e aliina (Lorenzi e Matos, 2002).

$\mathrm{O}$ alho é bastante utilizado na área da saúde, uma vez que os seus constituintes são proveitosos para o tratamento e prevenção de algumas doenças, esta erva aromática possui propriedades farmacológicas capazes de atuar a nível digestivo/intestinal, renal, respiratório (asma, bronquite) no tratamento da diabetes, da hipertensão arterial, esta planta possui componentes ativos anticarcinogênicos e quimiopreventivos, impedindo o aparecimento e a evolução de neoplasias (Corzo-Martínez et al., 2007). Alguns testes realizados in vitro, também apresentaram para o alho atividade antibacteriana, atribuída principalmente à alicina, que age na destruição e inibição de bactérias gram-negativas (Wu et al., 2001; Minler, 1996).

A utilização de novos métodos de tratamento com o uso de plantas ou extratos pode contribuir para a diminuição da dependência de medicamentos com patentes ou de altos custos, contribuindo para um tratamento mais humanizado mesmo invasivo e regionalizado (Badke et al., 2011).

A extração do óleo essencial do alho realizado através do sistema Clevenger usado na produção de pequena escala de extração de óleos vegetais. $\mathrm{O}$ sistema de arraste por vapor d'água e/ou destilação a vapor é o método mais utilizado e viável economicamente para extração de óleos vegetais.

O objetivo do presente estudo foi testar a sensibilidade in vitro do óleo essencial e do extrato do alho (Allium sativum L.) em bactéria causadora de infecção do trato urinário.

\section{MATERIAL E MÉTODOS}

Para escolha desse trabalho foi realizado uma coleta de dados no mês de julho de 2018, em um laboratório de análises clínicas, na cidade de Xinguara, município do Estado do Pará, onde se possui um banco de informações armazenadas no programa RV software. O banco de dados não possui informações pessoais como a identificação do paciente. Foi extraído algumas informações no sistema com as seguintes prerrogativas: a) positivo ou negativo para infecção; b) masculino ou feminino; c) idade, d) qual agente patológico estava presente. Logo após de coletados e analisados os dados, iniciou-se a pesquisa com testes laboratoriais.

As análises laboratoriais foram realizadas no laboratório de Microbiologia da Faculdade Integrada 
Carajás (FIC), na cidade de Redenção-PA entre meses de agosto a novembro de 2018.

\section{Metodologia de extração de óleo essencial}

O sistema de arraste por vapor d'água e/ou destilação a vapor é o método mais utilizado e viável economicamente para extração de óleos essenciais. Utilizando o aparelho Clevenger para extração de óleos essenciais, obtêm-se resultados econômicos mais viáveis e excelente qualidade no produto final.

Foi utilizado alho proveniente do comércio da cidade de Xinguara-PA, os bulbos frescos de Allium sativum L. in natura foram devidamente selecionados e pesados $(650 \mathrm{~g})$. Em seguida foram acrescidos $1000 \mathrm{~mL}$ de água destilada para auxiliar o processo de trituração no liquidificador para obtenção de uma biomassa. Em seguida, o balão de fundo redondo foi adaptado ao condensador e levado à manta aquecedora, que foi ligada e regulada à temperatura de 60 a $70 \mathrm{C}^{\circ}$, onde a biomassa foi depositada, dando início ao processo de extração de óleo essencial do alho por arraste de vapor de água. Esse ciclo de evaporação e condensação obteve-se continuamente por 15 horas quando então o sistema foi desligado e obtido o hidrolato.

A leitura do volume de óleo essencial extraído foi feita diretamente na escala volumétrica do tubo separador. Em seguida, o óleo foi coletado em frasco âmbar de $5 \mathrm{ml}$, onde foi coletado $1,5 \mathrm{ml}$ de óleo essencial e armazenado em lugar fresco e sem a incidência direta de luz.

\section{Procedimento de obtenção do extrato de alho}

Foram utilizados os bulbos frescos de Allium sativum L. in natura para a preparação de extrato vegetal, os mesmos adquiridos no comércio de Xinguara-PA. Os bulbos frescos, depois de selecionados e descascados foram imersos em solução de hipoclorito de sódio $(\mathrm{NaClO})$ na concentração $2,5 \%$ por 10 minutos, a fim de se promover sua desinfecção e garantir a esterilidade do extrato.

Utilizou-se $100 \mathrm{~g}$ de bulbos finamente fatiados e macerados manualmente. Após este processo, foi realizada a filtração, acondicionamento do filtrado em tubo de ensaio com tampa, os testes foram realizados no máximo 10 minutos após a filtração para que os princípios ativos não fossem alterados.

\section{Método de difusão em ágar - técnica de disco}

Foram utilizados discos de papel secos e estéreis, medindo $6 \mathrm{~mm}$ de diâmetro. Aos discos, e com pipeta de volume regulável entre $5-10 \mu \mathrm{L}$, foi transferido volume adequado de cada concentração 100 , 50 e $25 \%$ de óleo essencial de alho e de extrato de alho (Moreira et al., 2005). As placas contendo ágar Mueller Hinton preparadas antecipadamente foram retiradas da geladeira até atingir a temperatura ambiente. Com um swab estéril, o inóculo bacteriano de Escherichia coli foi distribuído uniformemente sobre a superfície do ágar em três direções, deixadas em repouso em temperatura ambiente por aproximadamente 3 minutos.

Utilizando-se pinça esterilizada, os discos, previamente impregnados com as soluções e os controles de ciprofloxacina e levofloxacina, foram distribuídos uniformemente sobre a superfície do ágar. As placas foram incubadas em estufa a $35 \pm 1^{\circ} \mathrm{C}$ por 24 horas. O halo de inibição do crescimento foi medido utilizando paquímetro digital. Os testes foram realizados em triplicata e em dias diferentes (Moreira et al., 2005).

Para melhor entendimento os dados foram tratados no programa $\mathrm{R}$, o R é uma linguagem e ambiente para computação estatístico e gráfico. $\mathrm{R}$ está disponível como software Livre sob os termos da Licença Pública Geral GNU da Free Software Foundation na forma de código fonte.

\section{RESULTADOS E DISCUSSÃO}

Os resultados da primeira pesquisa no qual foi realizada para a seleção das principais bactérias recorrentes nas infecções do trato urinário estão dispostas no gráfico abaixo. Das cem amostras analisadas sendo $23 \%$ positivo para o agente etiológico Escherichia coli, 8\% para os demais tipos de microrganismo, e $69 \%$ dos casos negativo para qualquer patógeno (Figura 1).

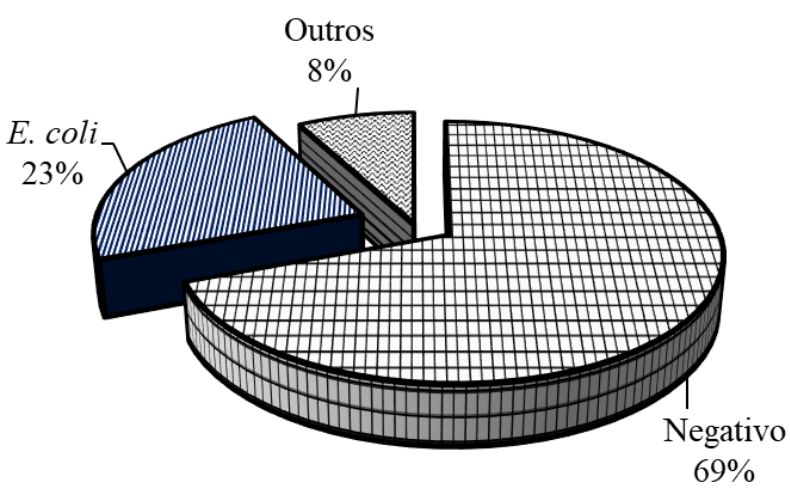

Figura 1 - Pesquisa da incidência de infecções e microrganismos causadores em percentual (\%).

Com base no resultado da pesquisa dos principais causadores de infecção urinária, é possível perceber uma nítida presença da Escherichia coli, nas infecções, sendo assim a maior causadora desta patologia. A infecção do trato urinário caracteriza-se 
pela invasão e multiplicação bacteriana em qualquer compartimento do aparelho urinário. Essa infecção pode acometer o trato urinário inferior e o superior (Andrade, 2005; Lopes e Tavares, 2005).

Considerando o gráfico de modo geral, foi possível verificar que quase $75 \%$ dos casos com infecção estão relacionadas com a presença da bactéria E. coli. De acordo com Lopes e Tavares (2005) a $E$. coli é o agente etiológico prevalente nas infecções do trato urinário sendo responsável por cerca de $80 \%$ das infecções em mulheres.

Roriz Filho et al. (2010), citam que a causa mais recorrente para tal infecção se dá pela má higienização principalmente do sexo feminino, onde afirmam que as mulheres tem uma maior incidência à infecção do trato urinário devido a sua estrutura anatômica, uretra mais curta e proximidade entre a vagina e o ânus.

Segundo Lopes e Tavares, (2005), o agente etiológico mais comum na infecção urinária é a $E$ coli, isso se dá por alguns fatores de risco, como a já citada higienização íntima precária, atividade sexual, métodos contraceptivos, imunidade comprometida, pouca ingestão de água.

Logo após a constatação do agente etiológico mais frequente nas infecções do trato urinário, foram aplicados os testes com extrato e óleo essencial do alho frente à bactéria encontrada. Os resultados das experiências de comparação entre o óleo essencial de alho e de seu extrato em relação a cepas de E. coli estão dispostas na Tabela 1.

Tabela 1 - Resultados obtidos das médias aritméticas das mensurações dos halos de inibição (Ø) em milímetros do óleo essencial e extrato de alho e seus controles frente a cepa E. coli em diferentes concentrações.

\begin{tabular}{ccccc}
\hline Concentração & $\begin{array}{c}\text { Óleo essencial } \\
\text { de alho }\end{array}$ & $\begin{array}{c}\text { Extrato de } \\
\text { alho }\end{array}$ & Ciprofloxacina & Levofloxacina \\
\hline $100 \%$ & 0 & $13,33 \pm 2,59$ & & \\
$50 \%$ & 0 & $9,22 \pm 1,48$ & $11,56 \pm 4,27$ & $13,44 \pm 3,43$ \\
$25 \%$ & 0 & $6,22 \pm 4,27$ & & \\
\hline Resultado & Não Eficaz & Eficaz & Eficaz (controle 1$)$ & Eficaz (controle 2$)$ \\
\hline
\end{tabular}

Diante dos resultados obtidos pelo método de difusão em disco, a espécie vegetal (Allium sativum L.) avaliada apresentou potencial antimicrobiano para o microrganismo testado E. coli.

A análise dos resultados do óleo essencial do alho não alcançou o resultado que se esperava, ou seja, não inibiu o microrganismo proposto, sendo assim, nas três concentrações não apresentaram eficácia. Já no extrato do alho para todas as concentrações obtiveram resultado satisfatório, onde o microrganismo testado foi sensível para o extrato. Portanto a concentração de $25 \%$ (halo criado 6,22 $\pm 4,27$ ) obteve o menor halo de inibição entre as três amostras, ficando entorno de metade dos halos dos antibióticos de controle. Já amostra do extrato com concentração de $50 \%$ (halo criado $9,22 \pm 1,48$ ), o halo produzido ficou próximo do halo de controle dos medicamentos tradicionais. Já na concentração do extrato a $100 \%$ (halo criado $13,33 \pm 2,59$ ), à sensibilidade do microrganismo obteve eficácia notável, onde se pode notar o paralelo entre o extrato e os antibióticos utilizados para controle, a mensuração dos halos obtiveram um comparativo semelhante, onde a diferencia é imperceptível a olho nu. Nos medicamentos de controle ciprofloxacina (halo criado $11,56 \pm 4,27$ ) e levofloxacina (halo criado $13,44 \pm 3,43$ ) respectivamente.

$\mathrm{O}$ alho possui uma quantidade muito grande de princípios ativos onde podemos destacar a alicina.
A alicina é liberada quanto o vegetal é triturado com ajuda da enzima alinase transformando-se em substância extremamente perceptível sensorialmente no que diz respeito ao sabor e odor característico do alho (Oomem et al., 2004).

Sendo a alicina a propriedade com a maior ação antimicrobiana do alho, a mesma é extremamente volátil, apesar de que o processo de extração do óleo essencial, pelo sistema fechado a vapor, pelo método de Clevenger, é provável que a quantidade que se perde no aquecimento seja muito grande, e que a literatura confirma, que a alicina liberada tem uma vida muito curta após a biotransformação, motivo este do insucesso frente à bactéria. Já no extrato do alho, o mesmo não sofreu aquecimento e a preservação de seus constituintes químicos se manteve, com suas propriedades praticamente inalteradas, principalmente os que são voláteis (Singh e Singh, 2008).

Portanto, a evidência que o óleo essencial do alho ficou prejudicado para ação antimicrobiana, comparada com a ação do então extrato do alho, pois, esse confirmou uma eficácia satisfatória junto à bactéria testada.

Verificou-se que o extrato de alho em outras concentrações também apresentou atividade antimicrobiana para o microrganismo testado, em comparação com óleo essencial de alho que não teve atividade antimicrobiana contra o microrganismo. 
Esses resultados encontram - se de acordo com os registrados por Deresse, (2010), no qual o alho fresco apresentou melhor atividade antibacteriana, uma vez que tal propriedade do extrato de alho é sensível ao calor e a alicina agente antibacteriano mais potente do extrato de alho.

Segundo Cunha, (2006), teste de sensibilidade antimicrobiana de extratos brutos de espécies vegetais, o potencial antimicrobiano, muitas vezes, não se deve a um princípio ativo, mas sim, a um conjunto desses. Um extrato bruto de uma espécie vegetal que tem efeito bactericida satisfatório poderia não necessitar, portanto, de processos de isolamento de substâncias ativas, reduzindo, assim, eta- pas químicas e, consequentemente, custos financeiros.

Quanto às diferentes concentrações do extrato de alho, verificou - se que todos apresentaram atividade antimicrobiana sobre os microrganismos testados.

$\mathrm{Na}$ análise do antibiograma onde se usou o óleo essencial do alho em concentrações diferentes, pode-se constatar que o mesmo não obteve inibição para o microrganismo testado. Onde se pode confirmar nas placas a semeaduras do patógeno com as cepas contendo os antibióticos e o óleo essencial, na Figura 2.
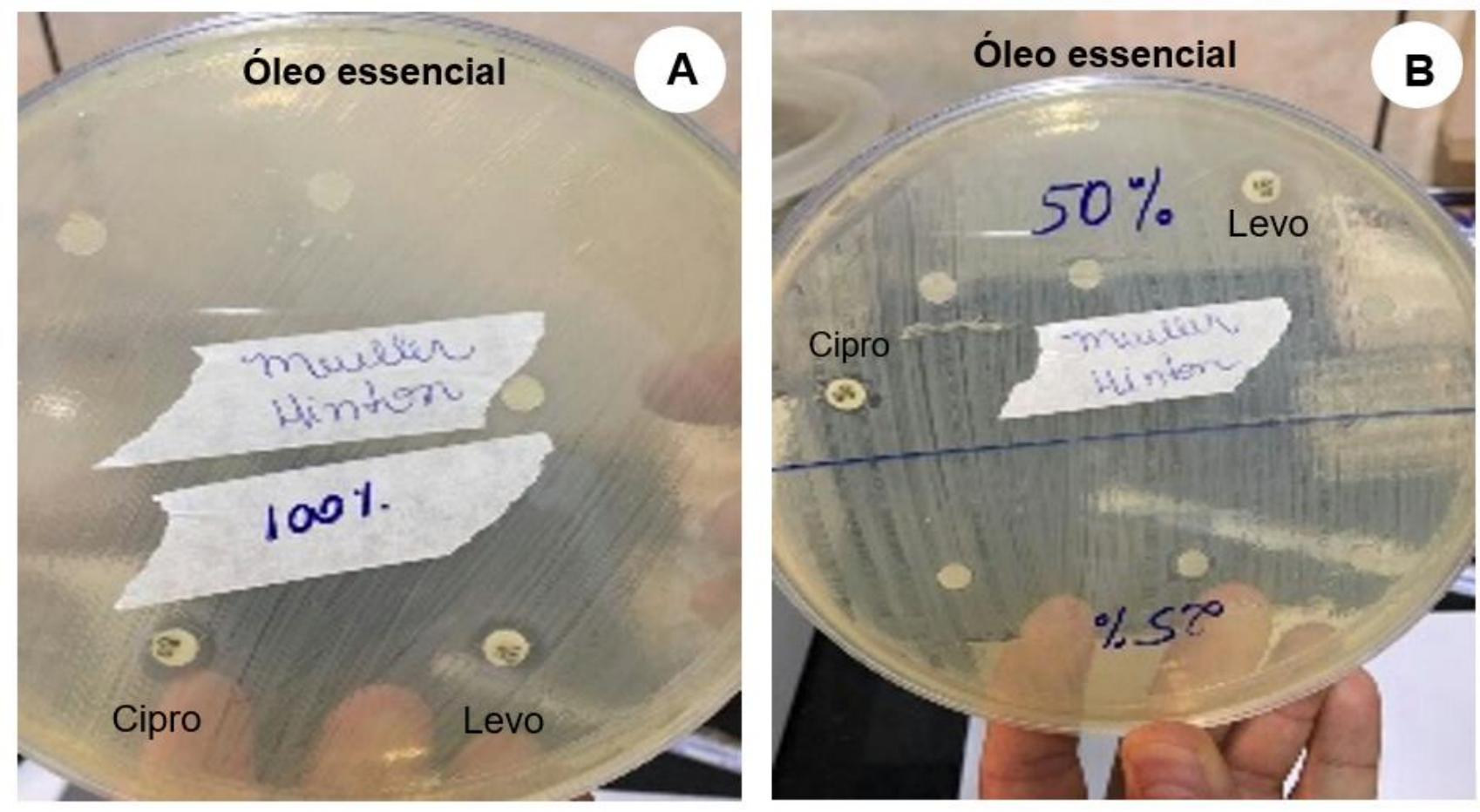

Figura 2 - A: Teste de difusão em ágar com óleo essencial $100 \%$ de alho frente a bactéria $E$. coli após 24 h de incubação. B teste de difusão em ágar com óleo essencial $50 \%$ e $25 \%$ de alho frente a bactéria $E$. coli após $24 \mathrm{~h}$ de incubação.

A confirmação de eficácia do extrato do alho frente à bactéria $E$. coli pose ser compreendida na leitura visual dos discos de inibição produzido junto ao microrganismo, onde o mesmo obteve halo de inibição paralelo ao do antibiótico usado como controle, a sensibilidade da bactéria ao extrato do alho é evidente e o êxito com este experimento e notado pela seguinte figura 3 .

A atividade foi diretamente proporcional à concentração do extrato. Pode ser observado que quanto maior o tamanho do halo de inibição medido em milímetros, melhor é o efeito in vitro do antimicrobiano.
O potencial antimicrobiano apresentado pelo extrato do Allium sativum L. pode estar relacionado à presença de taninos no mesmo, os quais são uma ótima substância antimicrobiana devido à sua capacidade de precipitar proteínas. À medida que ocorreu a diminuição da concentração do extrato, diminuiu também a concentração de taninos e, consequentemente, o poder antimicrobiano deste. A alicina constitui o principal fitoquímico biologicamente ativo com atividade antimicrobiana produzida pelo alho (Oomen et al., 2004). 


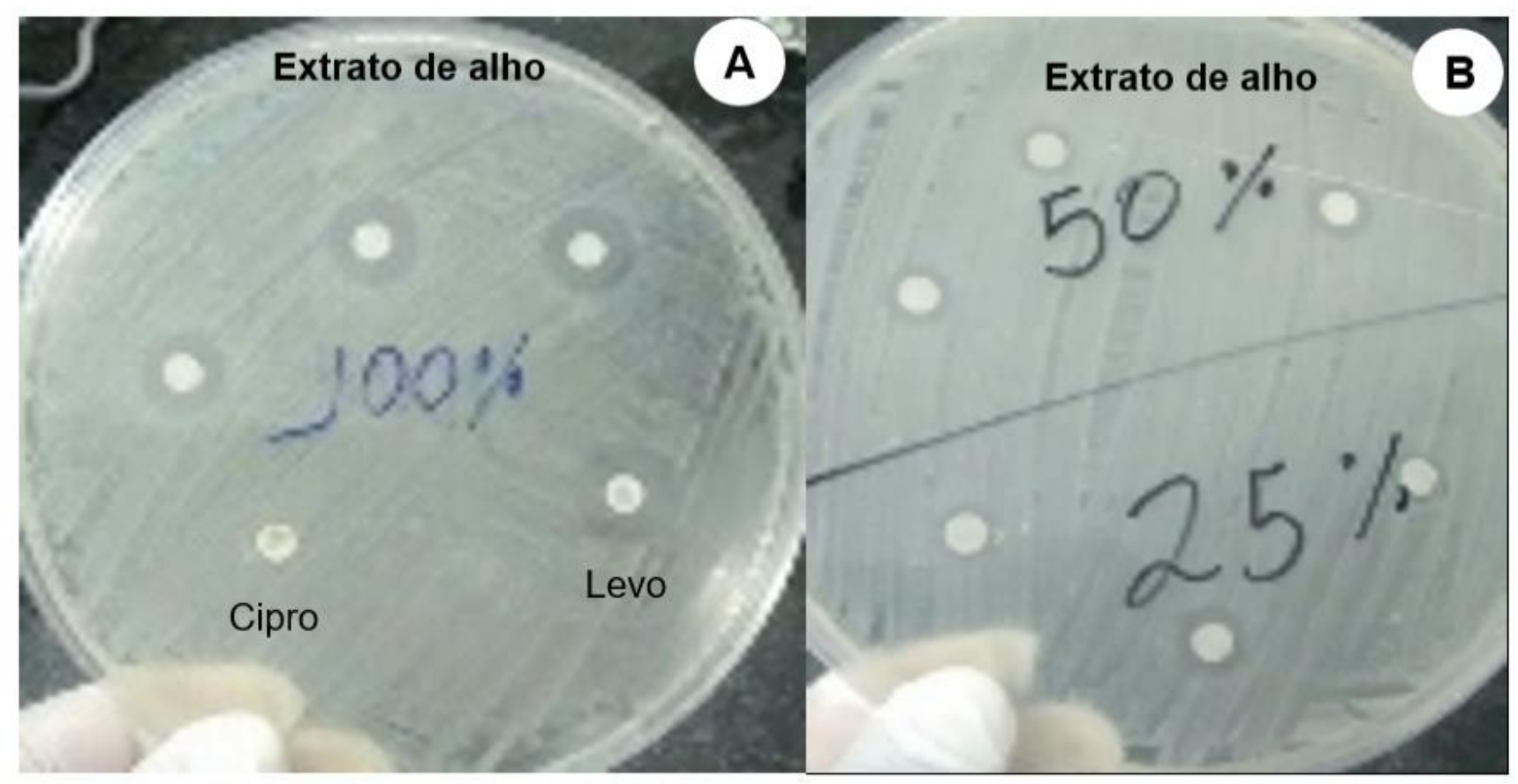

Figura 3 - A: Placas de petri no teste de difusão em ágar com E. coli após 24 h de incubação, na temperatura de $36^{\circ} \mathrm{C}$, com extrato de alho $100 \%$. B: Placas de petri no teste de difusão em ágar com E. coli após $24 \mathrm{~h}$ de incubação, na temperatura de $36^{\circ} \mathrm{C}$, com extrato de alho 50 e $25 \%$.

Os resultados foram comparados com testes não paramétricos com o auxílio de um gráfico de caixa onde é possível observar variáveis como média, medianas os limites inferiores e superiores das três concentrações em comparação com antibióticos de controle (ciprofloxacina e levofloxacina) (Figura 4).

Analisando a figura 4, observa-se que a concentração do extrato de alho a $100 \%$, apresentam resposta melhor do que os antibióticos de controle pela sua padronização dos halos, a diferença é bastante significativa quando comparadas concentração $100 \%$ com as concentrações 50 e $25 \%$ que apresentaram uma diminuição na atividade antimicrobiana.

De modo geral, o gráfico supracitado demostra a diferença significativa em relação às médias e a distribuição das frequências dos resultados encontrados nas concentrações do extrato de alho frente aos seus padrões. Como pode ser visto o extrato do alho na concentração $100 \%$ obteve média superior ao encontrado nos dois padrões. Esse fato demostra que a frequência de resultados encontrados no estudo para a contração de $100 \%$ é mais eficaz em termos estatísticos de média Kruskal Wallis e distribuição dos valores do que os controles ciprofloxacina e levofloxacina.

Analisando de modo mais específico, podemos observar que a mediana (valor representado pela linha no meio da barra) das concentrações $100 \%$ é também superior à dos dois padrões (ciprofloxacina e levofloxacina). Este fato se dá devido aos resultados das medições dos halos de inibição do extrato de alho serem, de modo específico, menos oscilantes do que os observados nos padrões.

Por outro lado, os resultados obtidos e evidenciados no gráfico de comparação (box plot), demostram também que as concentrações mais diluídas (50 e $25 \%$ ) obtiveram resultados abaixo dos prestados pelos padrões.

O potencial antimicrobiano do extrato de alho foi confirmado por meio de dos ensaios microbiológicos in vitro. Estes testes reforçam a utilização de fontes naturais como potenciais substâncias curativas. A evidência da considerável sensibilidade de $E$ coli frente ao extrato de alho foi positiva e portanto, a atividade do extrato de alho pode ser considerada com capacidade antimicrobiana ou ainda na verificação da resistência ou sensibilidade de outras bactérias (Lima, Câmara e Fonseca, 2014)

O uso indiscriminado de antibióticos pode ocasionar a uma seleção de microrganismos resistentes, ocasionando em problemas graves relacionadas a saúde pública, fazendo os tratamentos atuais serem cada vez mais caros e com utilização de uma quantidade muito maior de substâncias químicas inibidoras nos pacientes com alguma enfermidade bacteriana (Silva et al., 2013). 


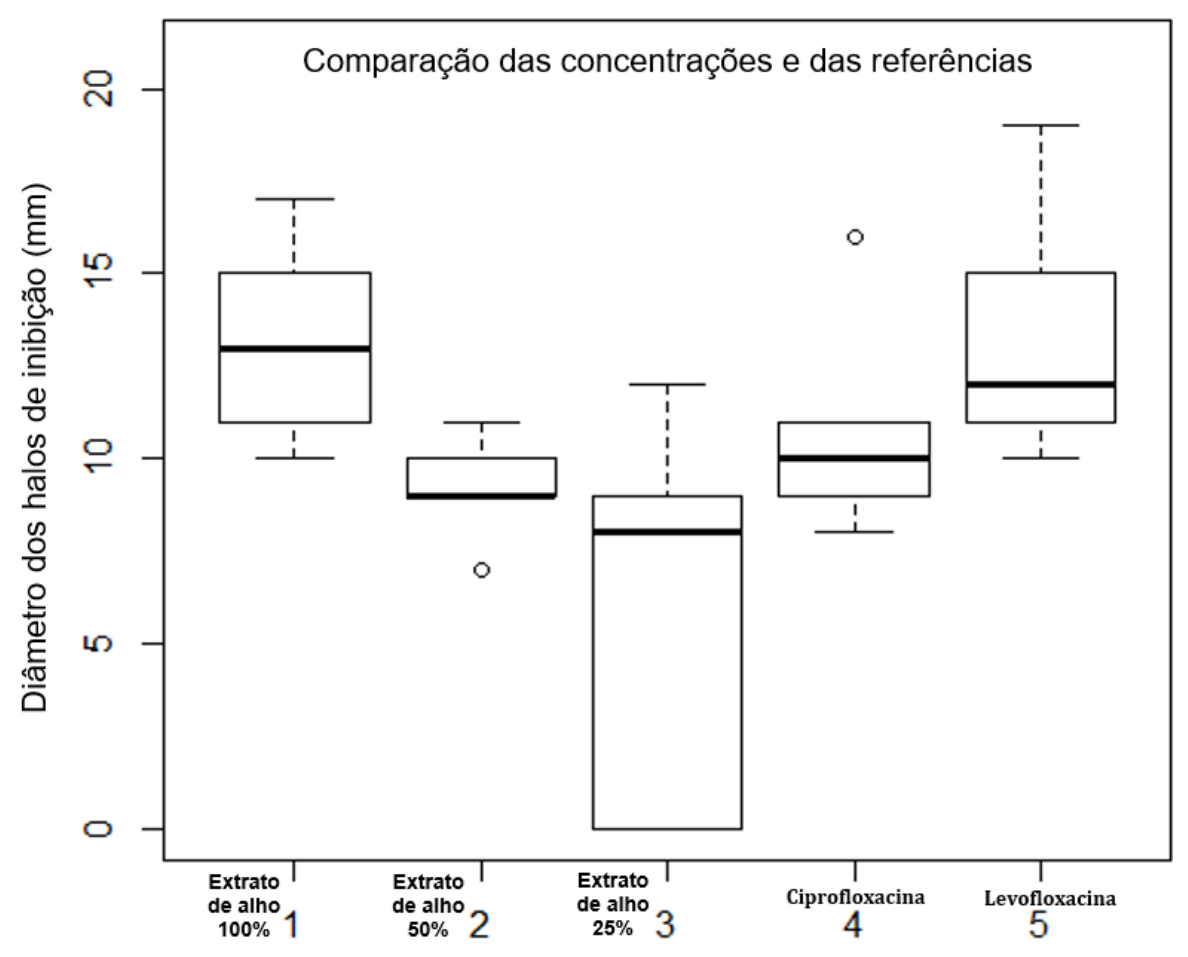

Figura 4 - Mediana do diâmetro dos halos de inibição de cada concentração do extrato de alho e antibiótico controle.

Ćirkovic et al., (2012), confirmaram a atividade antimicrobiana extrato de alho em investigação realizada por eles em diferentes bactérias gram-positivas e gram-negativas. Segundo Paur (2011), o alho tem ação antimicrobiana, inibindo o crescimento de fungos, vírus e várias bactérias Gram positivas e Gram negativas.

Em um estudo desenvolvido por Cohain (2010), in vivo, foi possível observar a ação do alho in natura frente a um amplo espectro de estreptococos patogênicos. $\mathrm{O}$ estudo utilizou pacientes que acometidas com infecção urinaria utilizando alho inseridos na região genital. O resultado foi satisfatório mostrando das nove mulheres, oito delas obtiveram resultados positivos em diminuição ou eliminação total das infecções após o uso.

A busca por plantas com atividade antimicrobiana tem aumentando principalmente devido ao desenvolvimento de resistência bacteriana, acentuado pelo uso desmedido e irracional de antibióticos industrializados (Silva e Fernandes, 2010).

O ritmo do desenvolvimento de resistência microbiana constitui um grande desafio terapêutico e uma preocupação mundial, pois paralelamente ao seu aumento houve uma diminuição no desenvolvimento de novas drogas antimicrobianas. Portanto, inúmeros trabalhos vêm sendo desenvolvidos em todo o mundo com intuito de identificar plantas ou substâncias com propriedades antimicrobianas, uma vez que as plantas produzem inúmeras substâncias biologicamente ativas, e muitos vegetais contêm compostos que são inibidores do crescimento de microrganismos. Assim tem-se nos produtos de origem vegetal uma fonte importante de recursos para a produção de novas drogas e medicamentos que façam uso de substâncias naturais principalmente de plantas (Rossi e Andreazzi, 2005).

\section{CONCLUSÕES}

Com base nos dados, foi constatado que apenas o extrato de alho apresentou atividade antimicrobiana nas três concentrações frente a bactéria $E$. coli. Foi verificado atividade antimicrobiana do extrato de alho em todas as concentrações (100\% $13,33 \pm 2,5950 \% \quad 9,22 \pm 1,48$ e $25 \% \quad 6,22 \pm 4,27$ ) sendo a concentração de $100 \%$ de extrato detentora de eficiência compatível com os controles ciprofloxacina $(11,56 \pm 4,27)$ e Levofloxacina $(13,44 \pm 3,43)$. O óleo essencial de alho não apresentou atividade antimicrobiana em nenhuma das concentrações frente ao microrganismo estudado devido a algumas diferenças químicas que existem do extrato frente aos óleos essenciais que são constituídos de substâncias que podem ser arrastadas na hidrodestilação. $\mathrm{O}$ extrato do alho se mostrou mais 
eficaz por contar com sua constituição íntegra e por não ter sofrido modificações devido a utilização de temperatura na sua obtenção. $\mathrm{O}$ extrato do alho pode vir a ser utilizado na formulação de cosméticos ou mesmo medicamentos fitoterápicos que tenham o objetivo de eliminar ou mesmo inibir o desenvolvimento de E. coli.

\section{REFERÊNCIAS BIBLIOGRÁFICAS}

ANDRADE, C.L. Histopatologia e identificação da Escherichia coli como agente causal da celulite aviária em frangos de corte. 2005. 62f. Dissertação de Mestrado (Mestrado em Med. Veterinária) - Universidade Federal Fluminense, Rio de Janeiro.

BADKE, M.R. et al. Plantas medicinais: o saber sustentado na prática do cotidiano popular. Escola Anna Nery, v.15, n.1, p.132-139, 2011.

ĆIRKOVIC, I.; JOVALEKC, M.; JEGOROC, B. In vitro antibacterial activity of garlic and synergism between garlic and antibacterial drugs. Arch Biol Sci. v.64, n.4, p.13691375. 2012.

COHAIN, J.S. Cases series: symptomatic group B 684 Rev. Bras. Pl. Med., Campinas, v.16, n.3, supl. I, p.679-684, 2014. Streptococcus vaginitis treated with fresh garlic. Integrative Medicine, v.9, n.3, p.40-43, 2010.

CORZO-MARTÍNEZ, M. et al. Biological properties of onions and garlic. Trends in Food Science \& Technology, v.18, n.12, p.609-625, 2007.

CUNHA, L.S. Avaliação da atividade antimicrobiana de extratos brutos de plantas do cerrado, substâncias isoladas e derivados semi sintéticos frente a microrganismos bucais. 2006. 170 f. Dissertação (Mestrado em Ciências) - Universidade de Franca, Franca, 2006

CUTLER, R.R.; WILSON, P. Antibacterial activity of a new, stable, aqueous extract of allicinagainst methicillin-resistant Staphylococcus aureus. British Journal of Biomedical Science.Londres, v.61, n.2, p.1-4, mar. 2004.

DERESSE, D. Antibacterial effetc of garlic (Allium sativum) on Sthaphylococcus aureus: Na in vitro study. Assian Journal of Medical Sciences. Awassa Ethiopia, v.2, n.2, p. 6265, mar. 2010.

GAZOLA, R.; SINGI, G.; RESENDE, R. Efeitos do extrato hidroalcoólico de Allium sativum (alho) sobre a pressão arterial média em ratos anestesiados. Revista Lecta. Bragança Paulista, v.20, n.2, p. 167-169, dez. 2002.

LIMA, D.X.; CÂMARA, F.P.; FONSECA. C.E.C. Urologia: Bases do Diagnóstico e Tratamento. 1. ed. São Paulo: Atheneu, 2014.

LIMA, M.R.F. et al. The antibiotic activity of some Brazilian medicinal plants. Brazilian Journal of Pharmacognosy, v.16, n.3, p.300-306, 2006.

LOPES, H.V; TAVARES, W. Diagnóstico das infecções do trato urinário. Revista da Associação Médica Brasileira, São Paulo, v.51, n.6, p.306-308, nov/dez. 2005.
LORENZI, H.; MATTOS, F.J.A. Plantas medicinais do Brasil: nativas e exóticas. Nova Odessa: Instituto Plantarum, 2002. 512p.

MINLER, J.A. (1996). Garlic: its anticarcinogenic and antitumorigenic properties. Nutr. Rev, v.54, p.82-86.

MOREIRA, M.R. et al. Inhibitory parameters of essential oils to reduce a foodborne pathogen. LWT-Food Science and Techonology, v.38, n.5, p.565-570, 2005.

OOMEN, S., ANTO, R.J., SRINIVAS, G.E.; KARUNAGARAN, D. Allicin (from garlic) induces caspase-mediated apoptosis in cancer cells. European Journal of Pharmacology, 485, p.97-103, 2004.

PAUR, I.E.A. (2011). Antioxidants in herbs and spices: roles in oxidative stress and redox signaling. Disponível em: http://www.ncbi.nlm.nih.gov/pubmed/22593932 Acesso em: 24/ junho/ 2018.

RORIZ FILHO, J.S. et al. Infecção do trato urinário. Revista da Faculdade de Medicina de Ribeirão Preto, v.43, n.2, p. 118-125, 2010. Disponível em: http://revista.fmrp.usp.br/2010/vol43n2/Simp3_Infec\%E7\%E3o\%20do\%20trato\%20urin\%E1rio.pdf. Acesso em: 30/ junho/ 2018.

ROSSI, F.; ANDREAZZI, D.B. Resistência bacteriana: interpretando o antibiograma. São Paulo: Atheneu, 2005. 118p.

SANDHU D.S.; HEINRICH, M. The use of health foods, spices and other botanicals in the Sikh community in London, Phytotherapy Research. v.1; n.9; p.633-642. 2005.

SILVA, D.; GELLEN, L.F.; SILVA, T.; COSTA, J.; SILVA, A.; SCHEIDT, G. Resíduos de antibiótico em leite: prevalência, danos à saúde e prejuízos na indústria de laticínios. Evidência - Ciência E Biotecnologia, v.13; n.2, p.137-152. 2013.

SILVA, N.C.C.; FERNANDES J.A. Biological properties of medicinal plants: a review of their antimicrobial activity. $\mathrm{J}$ Venom Anim Toxins incl Trop Dis. 2010; v.16; n.3; p.402413.

SINGH, V.K., SINGH D.K. Pharmacological effects of garlic (Allium sativum L.). ARBS Annu Rev Biomed Sci. 2008; v.10; p.6-26.

WU, C.; SHEEN, L.; CHEN, H.; TSAI, S.E.; LII, C. (2001). Effects of organosulfur compounds from garlic oil on the antioxidation system in rat liver and red blood cells. Food Chem Toxicol, v.39, p.563-569. 